\title{
PLANTAS INVASORAS DA CULTURA DO FEIJOEIRO (PHASEOLUS VULGARIS L.) NO ESTADO DE MINAS GERAIS.
}

\author{
Julio Pedro Laca-Buendia (1) \\ Mitzi Brandão (2) \\ Manuel Losada Gavilanes (3)
}

\begin{abstract}
RESUMO - Nas áreas de cultura do feijoeiro (Phaseolus vulgaris L.), no Estado de Minas Gerais, foram coletadas e identificadas 222 espécies de plantas invasoras (= plantas daninhas), pertencentes a 35 famílias botânias, representando 118 gêneros, sendo que as famílias Compositae, Leguminosae, Gramineae, Malvaceae, Convolvulaceae, Rubiaceae, Euphorbiaceae, Amaranthaceae, Cyperaceae e Solanaceae, são as mais importantes em relação à cultura. As plantas coletadas, devidamente etiquetadas e identificadas, foram anexadas no PAMG (Herbário da Empresa de Pesquisa Agropecuária de Minas Gerais, Belo Horizonte - (MG.).
\end{abstract}

Palavras-chaves: Phaseolus vulgaris, Plantas Daninhas, Daninhas do Feijoeiro.

ABSTRACT - A survey in the cultivation area of bean in the state of Minas Gerais, Brazil, resulted in the determination of 222 weeds species, of 118 genera belonging to 35 families presenting a greater number of species areas: Compositae, Leguminosae, Gramineae, Malvaceae, Convolvulaceae, Rubiaceae, Euphorbiaceae, Amaranthaceae, Cyperaceae and Solanaceae, with 33, 30, 25, 21, 12, 10. 10, 10, 9. 8 species respectively.

Key-words: Phaseolus vulgaris, weeds, bean weeds.

\section{Introduçāo}

As plantas invasoras de áreas cultivadas (plantas daninhas), quando crescem em solos agrícolas, com as plantas consideradas úteis, competem na extração dos elementos vitais: água, nutrientes, luz e dióxido de carbono $\left(\mathrm{CO}_{2}\right)$; em consequência, reduzem a produção agrícola (Zeep, 1971).

(1) Pesquisador da EPAMIG, Caixa Postal 515, 30.000 - Belo Horizonte, MG.

(2) Pesquisador da EPAMIG, Caixa Postal 515, 30.000 - Belo Horizonte, MG. Bolsista do CNPq.

(3) Professor de Botânica da ESAL, Caixa Postal 37. 37.200 - Lavras, MG. Bolsista do CNPq. 
Em culturas básicas tem-se como meta final um alto rendimento econômico, que venha minimizar não só os custos de sua implantação, dos cuidados culturais inerentes a mesma, como também as oscilaçôes do preço do produto no mercado. As perdas devido à competição entre espécies invasoras e culturas agrícolas, em todo o mundo, se situam em torno de 30 a $50 \%$ (Mani et al., 1968; Pereira \& Jones, 1954); no Brasil esses níveis são levemente superiores. Além da redução quantitativa da produção, todos os tipos de produtos agrícolas podem ser qualitativamente depreciados.

O cadastramento, a identificação, os estudos de fenologia, germinação, desenvolvimento, competição, etc., de plantas invasoras, ocorrentes em culturas, no Estado de Minas Gerais, objetivam subsidiar o seu controle e/ou erradicação, além de oferecer dados reais que permitam o reconhecimento dessas plantas, em nível de campo (Maia, 1978; Brandão et al., 1982 e 1984).

Alguns trabalhos sobre o tema, já foram desenvolvidos, não tendo, entretanto esgostado o assunto, assim como, efetivado o cadastramento total das espécies ocorrentes no Estado (Laca-Buendia et al., 1982 e 1984). Torna-se imprescindível o levantamento sistemático dessas plantas por cultura, visto que a maioria dos trabalhos feitos com herbicidas só cita aquelas mais frequentes e grande parte dos autores só as identifica pelo seu nome genérico, ou popular, como por exemplo: Silva \& Silva (1984).

São objetivos principais deste trabalho:

a. Proporcionar referências para a identificação das plantas invasoras, que competem com a cultura do Feijoeiro (Phaseolus vugaris L.), no Estado de Minas Gerais;

b. Dar subsídios aos técnicos em herbicidas a fim de que possam reconhecer as plantas invasoras ocorrentes em culturas do Feijoeiro, dentro do Estado de Minas Gerais;

c. Continuar, em face da elativa escassez de dados sobre plantas invasora em terras mineiras, o levantamento das espécies, do ponto de vita botânico, iniciado com o levantamento das espécies ocorrentes na cultura algodoeira (Laca-Buendia et al., 1975).

\section{Material e Métodos}

Foram realizadas coletas de plantas invasoras da cultura do Feijoeiro (Phaseolus vulgaris L.) em quase todas as microrregiōes do Estado de Minas Gerais, visto ser essa uma cultura considerada de subsistência, tradicionalmente explorada por pequenos agricultores, que continuam sendo os principais produtores dessa leguminosa, plantando em pequenas áreas, em diferentes climas e solos.

Devido á introdução da irrigação, e a implantação de vários "Pivôs Central", ao longo do vale do Rio São Franciscu e em alguns Municípios do Triângulo Mineiro, a sua área de cultivo foi ampliada, razão pela qual intensificamos as coletas nessas regiões.

Em cada microrregião foram percorridos vários municípios e visitadas as 
Plantas invasoras da cultura do feijoeiro...

fazendas mais representativas em termos de seu cultivo.

As plantas coletadas foram identificadas segundo a metodologia clássica, rotuladas, registradas e anexadas ao PAMG (Herbário da EPAMIG).

O grau de ocorrência (abundância) de cada espécie foi estimado segundo as escalas semi-quantitativa de Hanson e qualitativa de Tansley \& Chipp., citadas por Blanco (1977), com algumas modificações, a saber: Esporádica - 1 a 2 plantas $/ \mathrm{m}^{2}$; Pouco Frequente - 3 a 6 plantas $/ \mathrm{m}^{2}$; Frequente - 7 a 10 plantas $/ \mathrm{m}^{2}$; Abundante - 11 a 50 plantas $/ \mathrm{m}^{2}$; Muito Abundante - + de 50 plantas $/ \mathrm{m}^{2}$.

\section{Resultados e Discussōes}

Foram identificadas, até o presente momento, no Estado de Minas Gerais, 222 espécies, de plantas invasoras da cultura do feijoeiro, pertencentes a 118 gêneros, englobados em 35 famílias. As espécies foram listadas por ordem alfabética das famílias e gêneros, seguidas de número de registro no PAMG, de seu(s) nome(s) popular(es), bem como do grau de abundância. As plantas em questão estão relacionadas na Tabela I. Na Tabela II as famílias estão ordenadas por ordem alfabética, seguidas do número de gêneros e de espécies encontradas.

Constatou-se a presença de 32 famílias de dicotiledôneas e 3 de monocotiledôneas. As famílias mais representativas foram: Compositae com 33 espécies englobadas em 25 gêneros, Leguminosae com 30 espécies em 10 gêneros, Gramineae com 25 espécies em 18 gêneros, Malvaceae com 21 espécies em 6 gêneros, Convolvulaceae com 12 espécies em 2 gêneros, Amaranthaceae, Euphorbiaceae e Rubiaceae, com 10 espécies em 4 gêneros, cada uma.

As espécies mais importantes, em relação à cultura, em enfoque, devido ao alto grau de abundância (muito abundante), foram : Acanthospermum australe (CARRAPICHO-DE-CARNEIRO), Ageratum conyzoides (ERVA-DE-SÃOJOÃO), Alternanthera ficoidea (SEMPRE VIVA), Amaranthus viridis (CARURU-MANCHADO), Bidens pilosa (PICÃO), Borreria alata (POAIA-ROXA), Brachiaria plantaginea (CAPIM-MARMELADA), Cassia tora (FEDEGOSO), Cenchrus echinatus (CAPIM-CARRAPICHO), Cynodon dactylon (GRAMA-SEDA), Cyperus rotundus (TIRIRICA-VERMELHA), Digitaria sanguinalis (MILHÃ), Eleusine indica (CAPIM-PÉ-DE-GALINHA), Emilia sonchifolia (PINCEL), Euphorbia heterophylla (LEITEIRA), Galinsoga parviflora (FAZENDEIRO), Ipomoea acuminata (CORDA-DE-VIOLA), Leonorus sibiricus (MACAÉ), Oxalis oxyptera (TREVO), Phyllanthus corcovandensis (ERVA-POMBINHA), Portulaca oleracea (BELDROEGA), Raphanus raphanistrum (NABIÇA), Sida rhombifolia (GUANXUMA), Sonchus oleraceus (SERRALHA-BRAVA).

Comparando-se a relação das plantas aqui apresentadas (Tabela I) com a listagem de plantas para a cultura do Feijoeiro em Minas Gerais, elaborada por Brandão et al. (1982), verifica-se que apenas 33\% das plantas já foram citadas. Isto mostra a necessidade de se efetuarem, e/ou ampliarem, levantamentos regionais das invasoras, por culturas, para que se possa estabelecer programas 
mais confiáveis no controle das mesmas.

O uso do binômio completo, isto é, a identificação taxonômica correta de uma espécie, vem esclarecer uma série de problemas impostos, mas não devidamente explicados pelos autores, ou seja, aqueles do comportamento e desenvolvimento da espécie visada em seus trabalhos. Espécies distintas, pertencentes ao mesmo gênero, podem ter hábitos completamente diversos e, portanto, formas variadas de ação sobre as plantas com as quais competem. Por exemplo, uma planta de hábito escandente compete em termos de luz, muito mais que uma de hábito ereto. Os tipos de raiz, a forma de sua distribuição, a rapidez de seu desenvolvimento e o ciclo evolutivo de certas espécies podem exigir uma soma maior de nutrientes e, portanto, serem competidoras em outro nível com as plantas cultivadas.

Sendo a citação feita corretamente, tem-se outra visão dos reais efeitos da competição, da forma de competição, do conhecimento do comportamento da planta invasora em enfoque, facilitando, por outro lado, uma seleção prévia daquelas mais competidoras, tendo como resultado, pesquisas adequadas que visem o controle e/ou erradicação dessas espécies.

\section{Referências Bibliográficas}

BLANCO, H.C. 1977. Plantas daninhas e mato competição. Boletim Informativo, Herbicidas em Florestas, Piracicaba, 1(77): 1-88.

BRANDÃO, M.; LACA-BUENDIA, J.P. \& GAVILANES, M.L. 1982. Principais plantas daninhas no Estado de Minas Gerais. Informe Agropecuário, Belo Horizonte, 8(87): 18-26.

BRANDÃO, M.; LACA-BUENDIA, J.P. \& GAVILANES, M.L. 1984. Plantas daninhas ocorrentes em áreas de culturas de soja (Glycine max (L.) Merril) no Estado de Minas Gerais. IN: CONGRESSO NACIONAL DE BOTÂNICA, 24, Porto Alegre, 1983. Anais... Porto Alegre, p. 235-249.

LACA-BUENDIA, J.P.; FERREIRA, M.B. \& GAVILANES, M.L. 1975. Contribuição para o conhecimento das ervas daninhas nas principais regioes algodoeiras em áreas de cerrado. Cerrado, Brasília, 6(28): 28-32.

MAIA, A.C. 1978. Controle de plantas daninhas. Informe Agropecuária. Belo Horizonte, 4(43): 28-29.

MANI, V.S. et al. 1968. Losses in crop yield in India due to weed growth. Pans, 14(2): 142-158.

PEREIRA, H.C. \& JONES, P.A. 1954. A tillage shedy in Kenya Coffee. Part I. The effects of tillage pratices on coffe yieldes. The Empire Journal of Experimental Agriculture, 22: 231-241.

SILVA, J.F. da \& SILVA, N.C. da 1984. Controle de plantas daninhas em feijāo (Phaseolus vulgaris $\mathrm{L}$.) consorciado com outras culturas. Informe Agropecuário, Belo Horizonte, 1O(118): 70-74.

ZEEP, W.V. der. 1971. Consequences of modern weed control for crop growning technique. Pans, 17(1): 20-25. 
Plantas invasoras da cultura do feijoeiro...

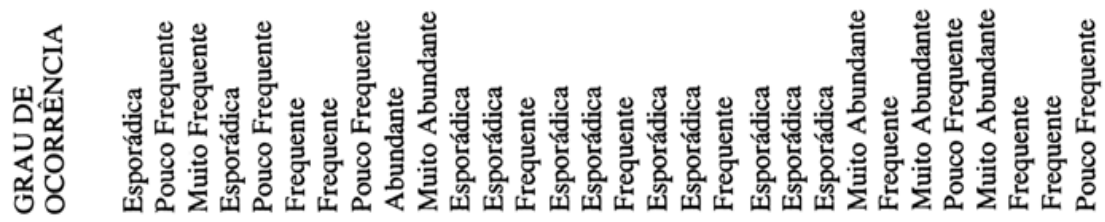

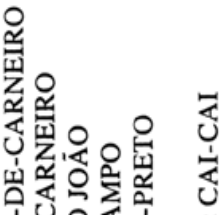

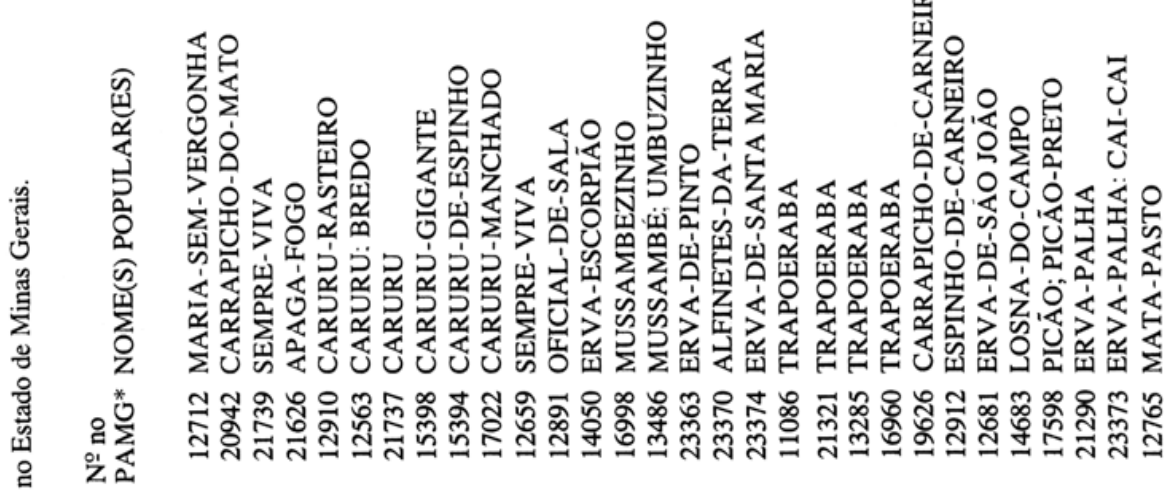

윯

ঃ

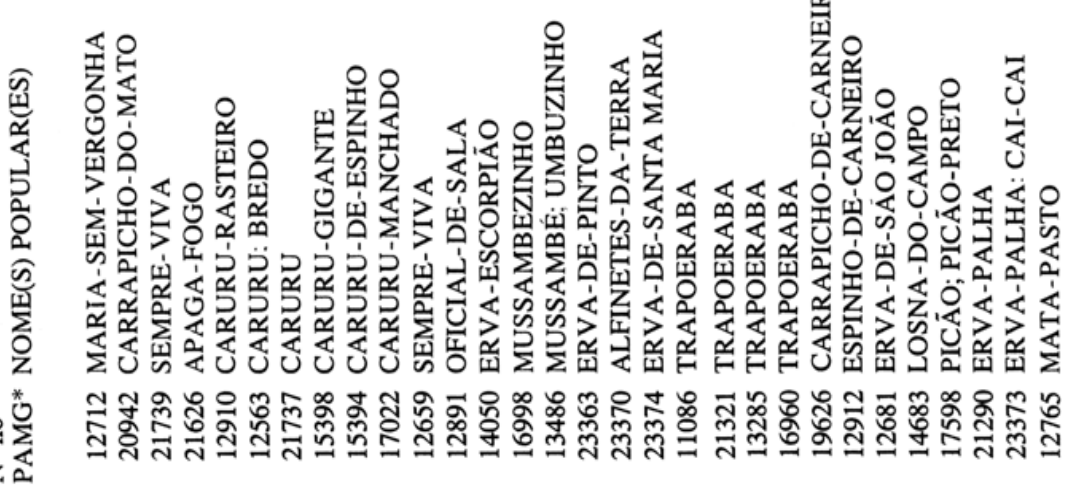

志

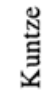

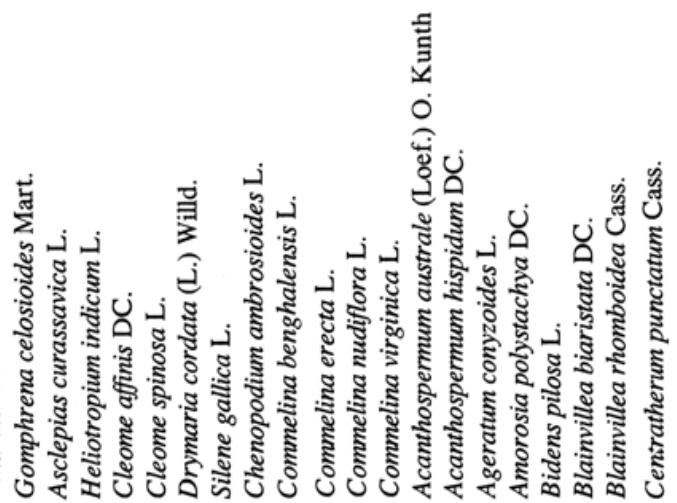

窇

离:

롤

i $\quad$

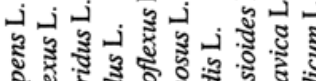

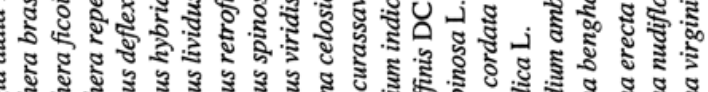

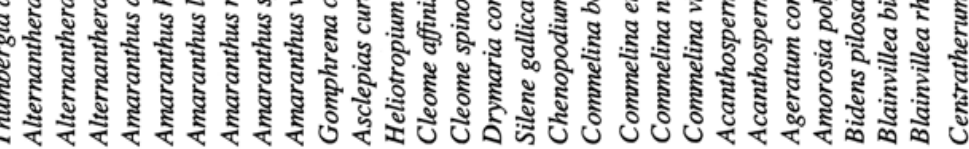

先

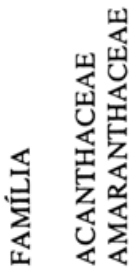

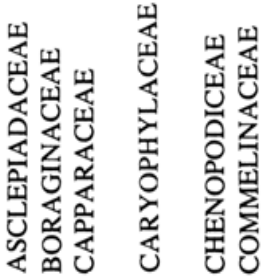

崖 


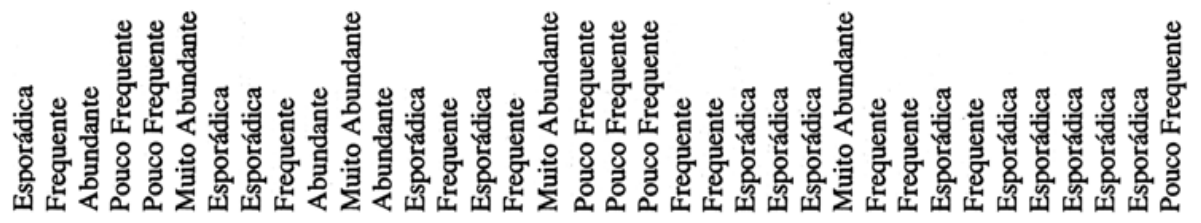

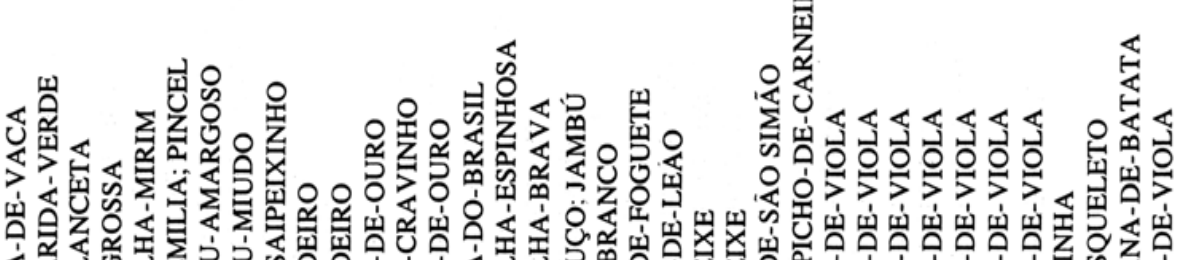

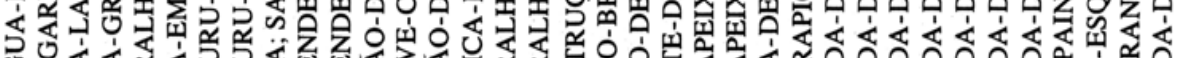

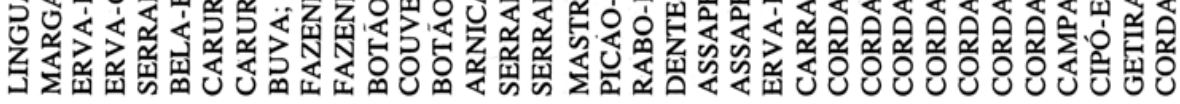
ๆ

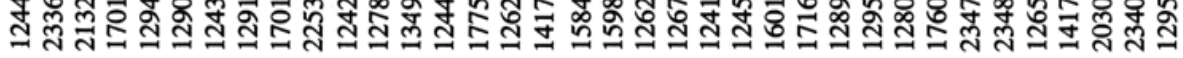

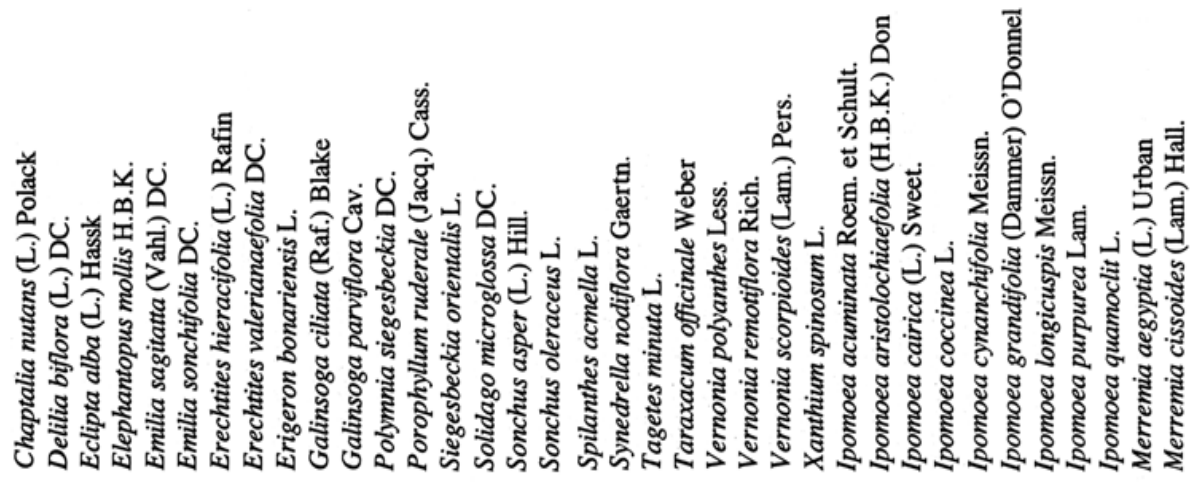


Plantas invasoras da cultura do feijoeiro...

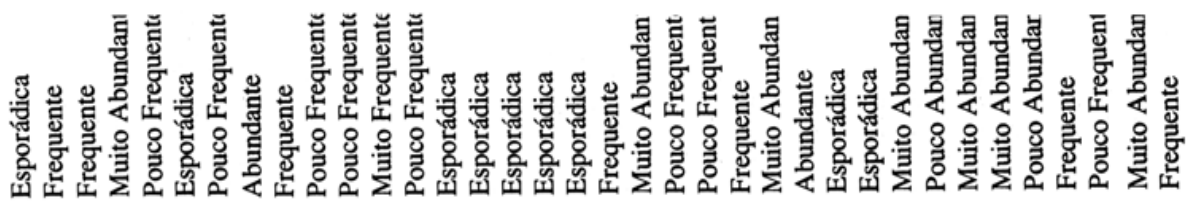

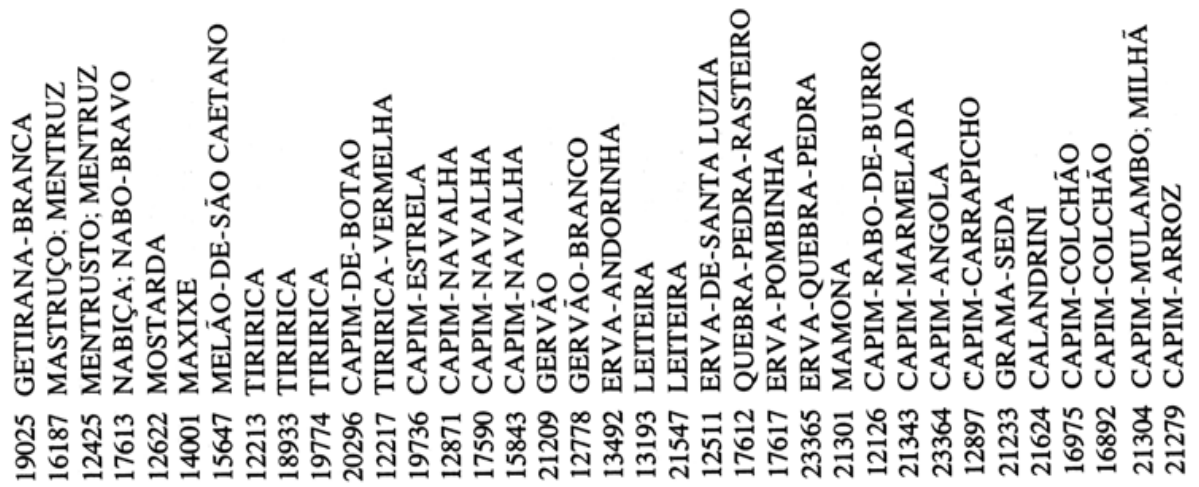
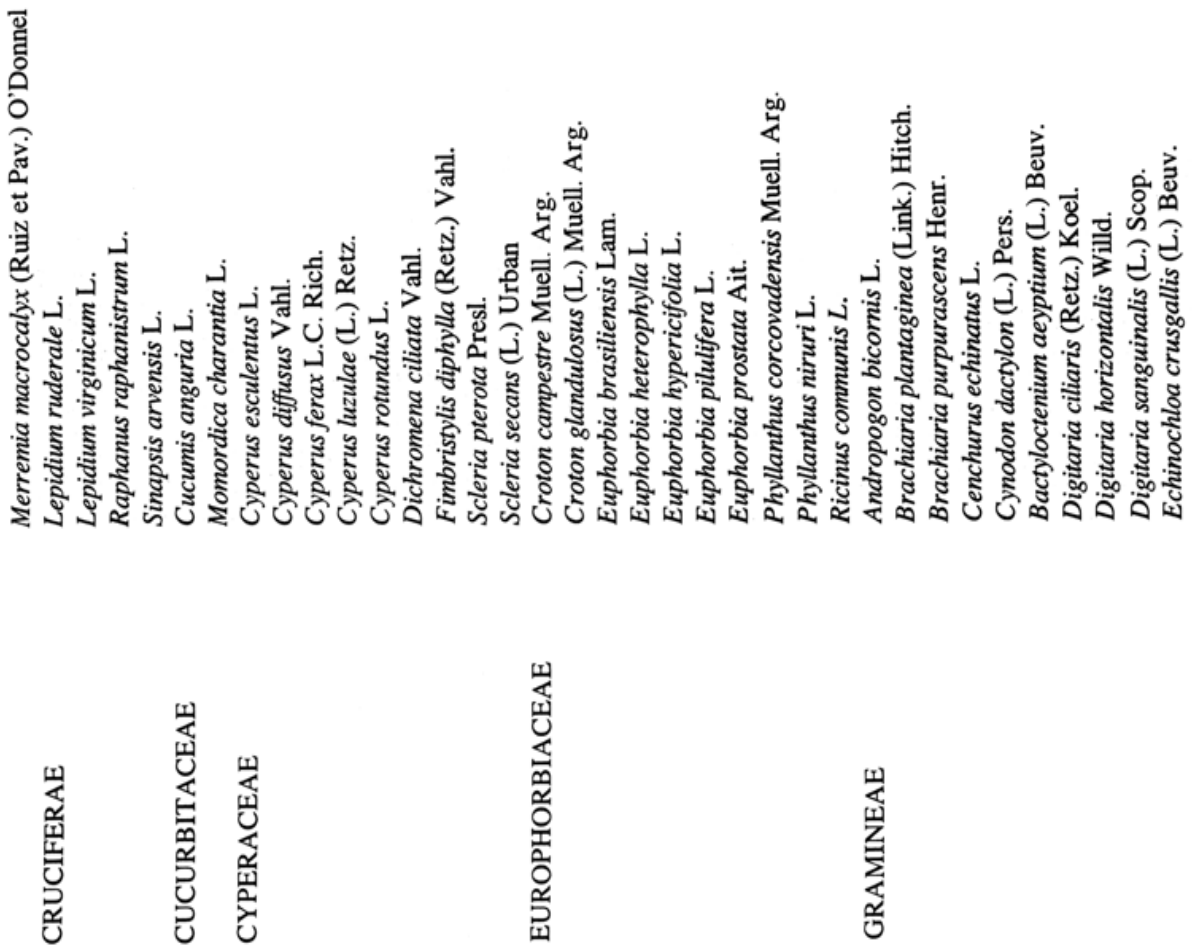


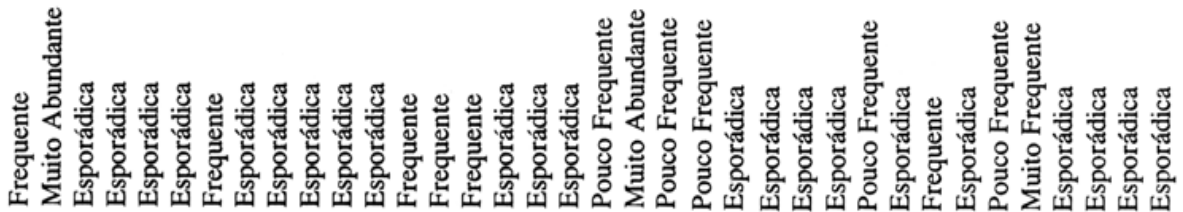

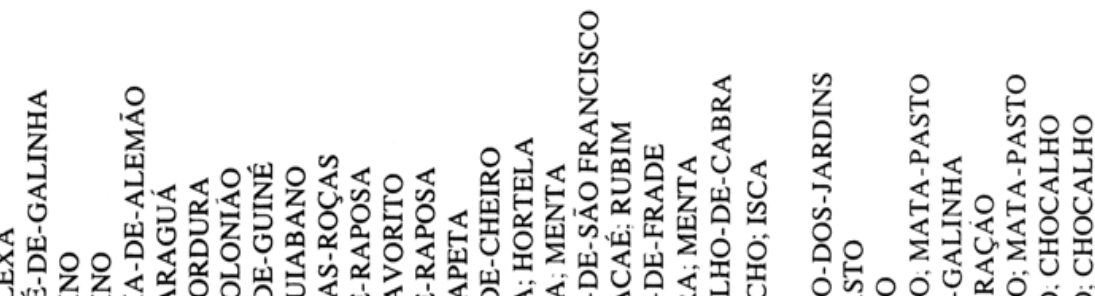

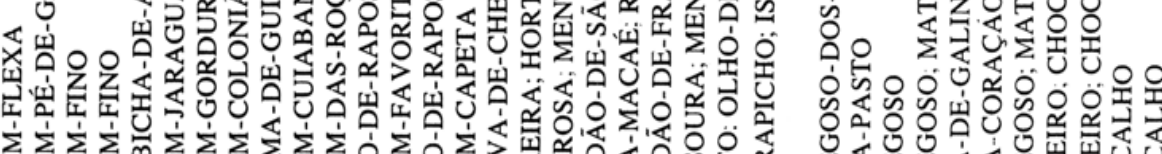

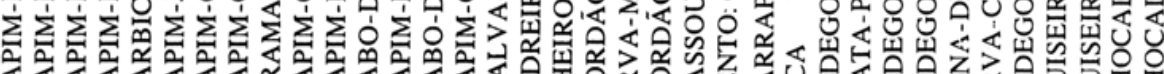

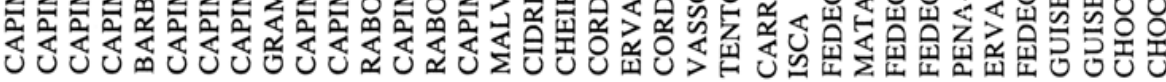

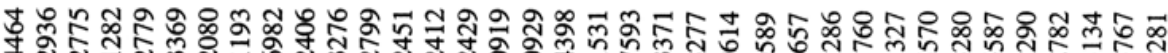

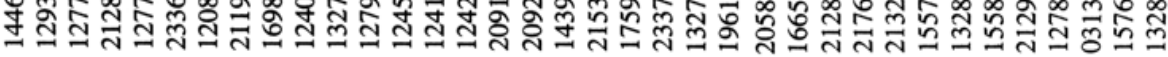
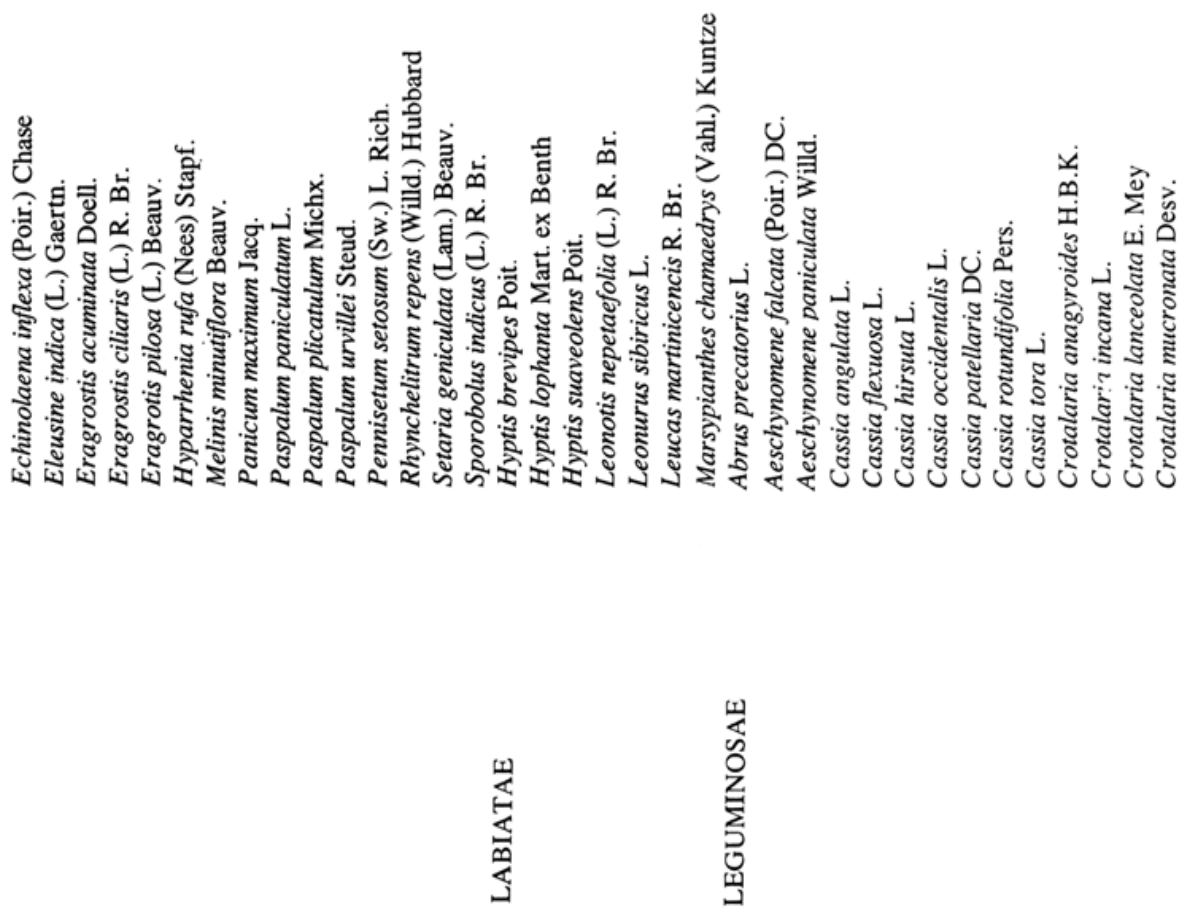

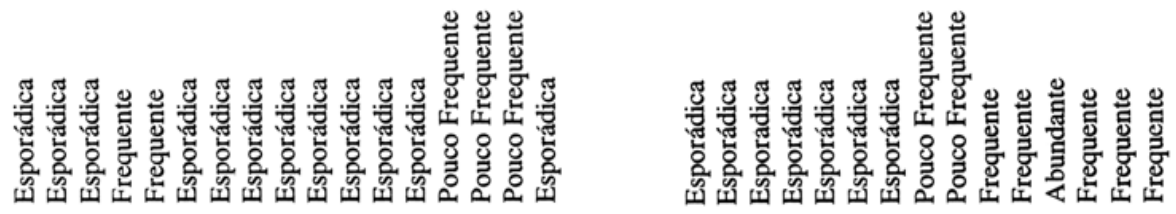

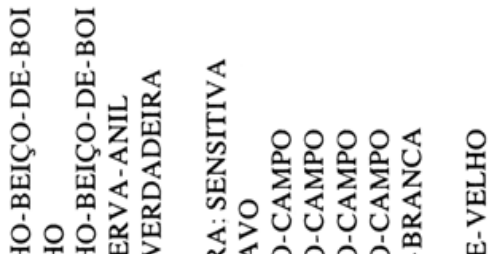

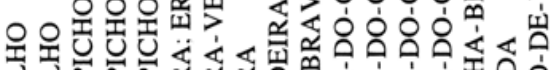

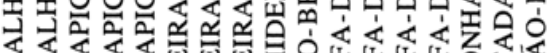

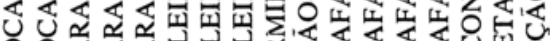

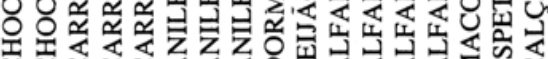

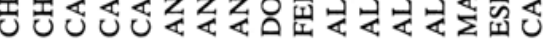

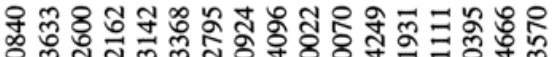

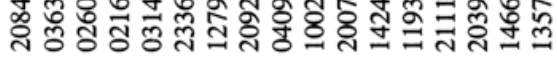

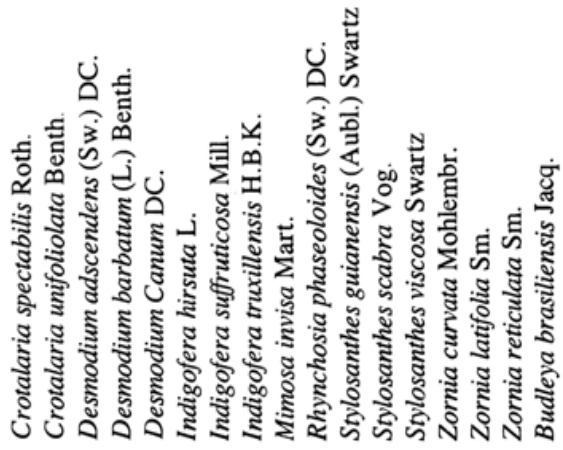

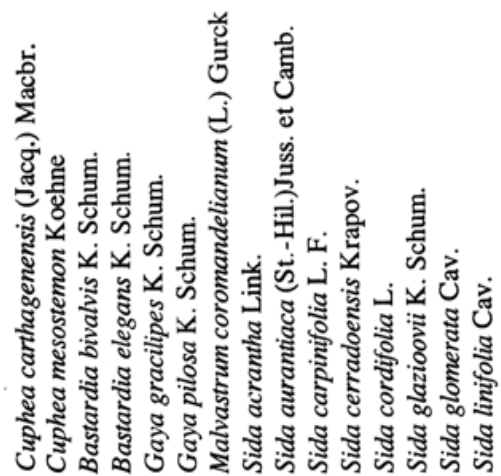

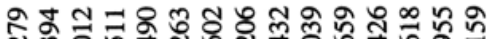

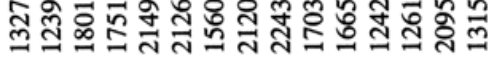



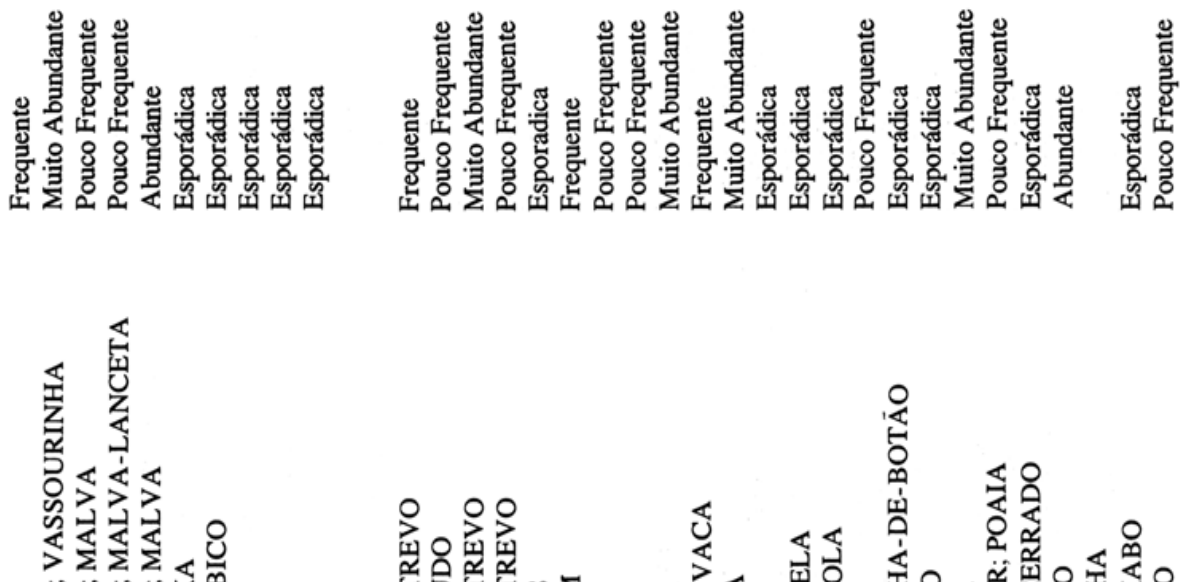

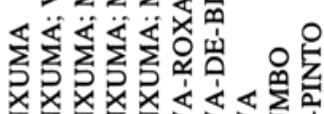
20.

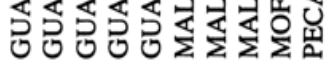

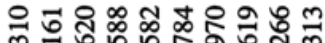

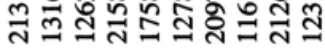
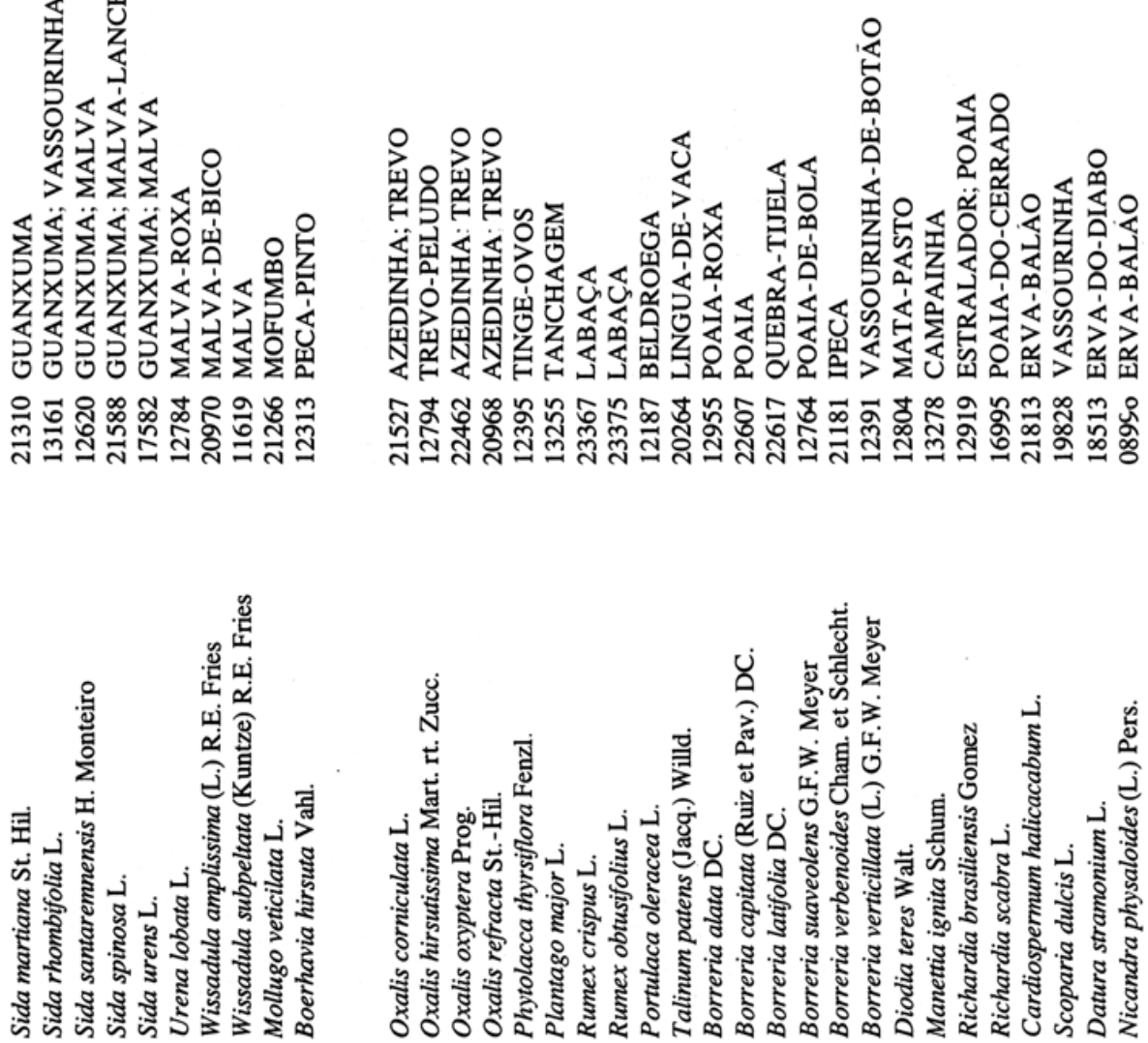

\begin{tabular}{|c|c|c|}
\hline 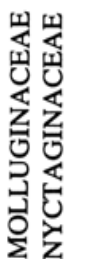 & 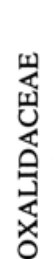 & 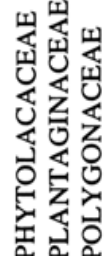 \\
\hline
\end{tabular}

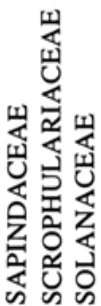


Plantas invasoras da cultura do feijoeiro...
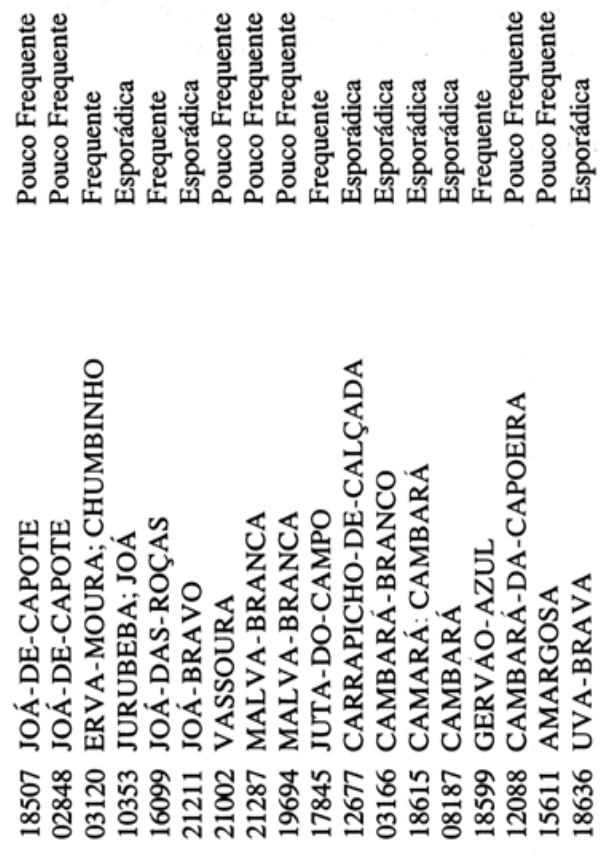

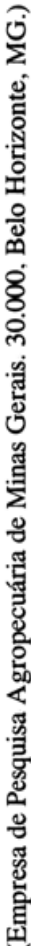

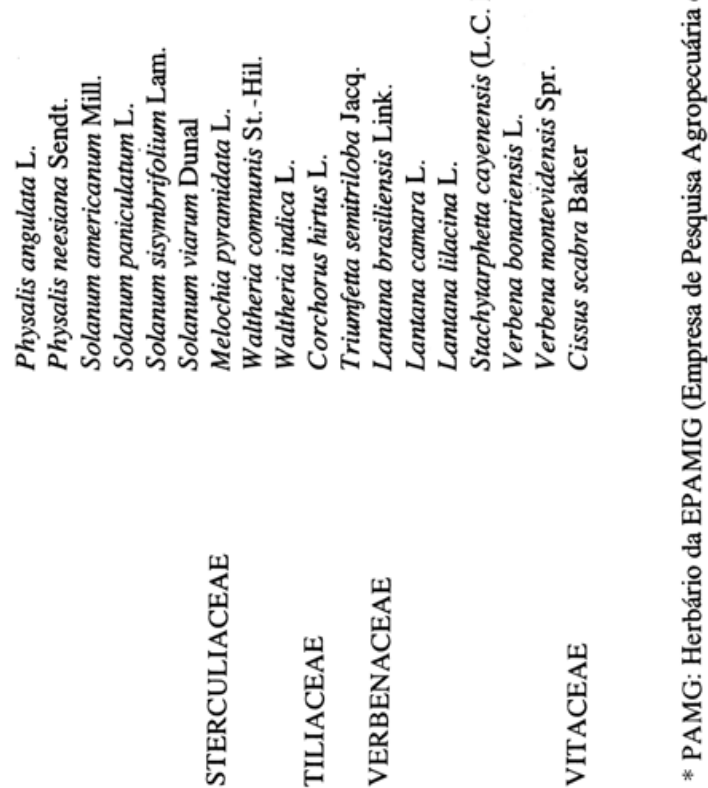


Tabela II - Familias, número de gêneros e número de espécies de plantas invasoras da cultura do Feijoeiro (Phaseolus vulgaris L.) no estado de Minas Gerais.

FAMÍLIAS

ACANTHACEAE

AMARANTHACEAE

ASCLEPIADACEAE

BORAGINACEAE

CAPPARACEAE

CARYOPHYLACEAE

CHENOPODICEAE

COMMELINACEAE

COMPOSITAE

CONVOLVULACEAE

CRUCIFERAE

CUCURBITACEAE

CYPERACEAE

EUPHORBIACEAE

GRAMINEAE

LABIATAE

LEGUMINOSAE

LOGANIACEAE

LYTHRACEAE

MALVACEAE

MOLLUGINACEAE

NYCTAGINACEAE

OXALIDACEAE

PHYTOLACACEAE

PLANTAGINACEAE

POLYGONACEAE

PORTULACACEAE

RUBIACEAE

SAPINDACEAE

SCROPHULARIACEAE

SOLANACEAE

STERCULIACEAE

TILIACEAE

VERBENACEAE

VITACEAE
GÊNEROS ESPÉCIES

$\begin{array}{rr}1 & 1 \\ 3 & 10 \\ 1 & 1 \\ 1 & 1 \\ 1 & 2 \\ 2 & 2 \\ 1 & 1 \\ 1 & 4 \\ 25 & 33 \\ 2 & 12 \\ 3 & 4 \\ 2 & 2 \\ 4 & 9 \\ 4 & 10 \\ 18 & 25 \\ 5 & 7 \\ 10 & 30 \\ 1 & 1 \\ 1 & 2 \\ 6 & 21 \\ 1 & 1 \\ 1 & 1 \\ 1 & 4 \\ 1 & 1 \\ 1 & 1 \\ 1 & 2 \\ 2 & 2 \\ 4 & 10 \\ 1 & 1 \\ 1 & 1 \\ 4 & 8 \\ 2 & 3 \\ 2 & 2 \\ 3 & 6 \\ 1 & 1\end{array}$

\footnotetext{
TOTAL - 35 famílias

118 gêneros

222 espécies
} 